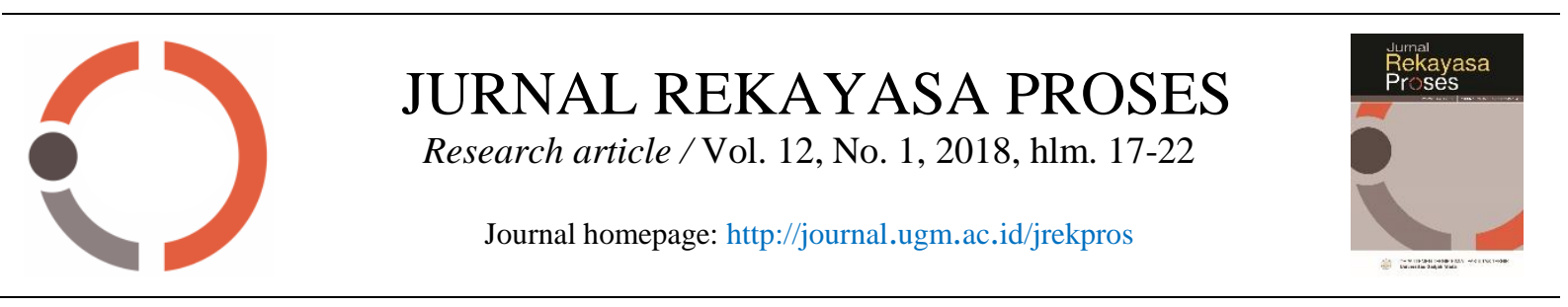

\title{
Sintesis dan Karakterisasi Silika Tersulfatasi dari Sekam Padi
}

\author{
Idra Herlina ${ }^{1}$, Edwin Rizki Safitra ${ }^{2}$ \\ ${ }^{1}$ Program Studi Kimia, Fakultas Matematika dan Sains, Institut Teknologi Sumatera \\ Jalan Terusan Ryacudu, Way Hui, Jati Agung, Lampung Selatan 35365 \\ ${ }^{2}$ Program Studi Teknik Kimia, Fakultas Teknologi Industri, Institut Teknologi Sumatera \\ Jalan Terusan Ryacudu, Way Hui, Jati Agung, Lampung Selatan 35365 \\ *Alamat korespondensi: idra.herlina@ki.itera.ac.id
}

(Submisi: 27 Maret 2018; Revisi: 23 April 2018; Penerimaan: 26 April 2018)

\section{A B S T R A C T}

In this work, sulphated silica $\left(\mathrm{SiO}_{2} / \mathrm{SO}_{3}{ }^{-} \mathrm{H}^{+}\right)$has been synthesized from rice husk through sol-gel method. Characterization with IR spectrophotometers showed similar peak between silica and sulphated silica. Silica typical bands consisting of strain $\mathrm{O}-\mathrm{H}$, bending water molecules, and asymmetric vibrations of silica atoms present in the siloxane appear at the peak of the analysis showing that silica synthesis of rice husk has been successfully performed. The modification of silica with sulphuric acid was not confirmed by IR spectrophotometers because the S-OH strain of sulphate ions overlaps with asymmetric vibrations of silica atoms present in siloxanes. The resulting sulphated silica was used as a catalyst in the esterification reaction of free fatty acid in a crude palm oil pond (Pond CPO). Pond CPO is a CPO that is bound to palm oil mill waste water. Pond CPO has free fatty acid content (FFA) between 40 to $70 \%$. High levels of FFA CPO can be derived through esterification reactions with the help of $\mathrm{SiO}_{2} / \mathrm{SO}_{3}{ }^{-} \mathrm{H}^{+}$catalyst. In this study, $\mathrm{SiO}_{2} / \mathrm{SO}_{3}{ }_{3} \mathrm{H}^{+}$catalyst concentrations were varied i.e. 1,3 , and $5 \%(w / w)$. From the research result, the best catalyst performance was obtained at 5\% concentration with the ability to decrease the FFA level by $49.70 \%$.

Keywords: sulfated silica, rice husk, sol-gel, CPO pond, esterification

\section{A B S T R A K}

Pada penelitian ini, silika tersulfatasi $\left(\mathrm{SiO}_{2} / \mathrm{SO}_{3}{ }^{-} \mathrm{H}^{+}\right)$dibuat dari sekam padi melalui metode sol-gel. Karakterisasi dengan spektrofotometer IR menunjukkan puncak yang serupa antara silika dan silika tersulfatasi. Pita khas silika yang terdiri dari regangan $\mathrm{O}-\mathrm{H}$, bengkokan molekul air, dan vibrasi asimetrik atom silika yang ada pada siloksan muncul pada puncak hasil analisis yang menunjukkan bahwa sintesis silika dari sekam padi telah berhasil dilakukan. Modifikasi silika dengan asam sulfat tidak terkonfirmasi melalui spektrofotometer IR karena regangan S-OH dari ion sulfat tumpang tindih dengan vibrasi asimetrik atom silika yang ada pada siloksan. Silika tersulfatasi yang dihasilkan digunakan sebagai katalis pada reaksi esterifikasi asam lemak bebas crude palm oil (CPO) parit. CPO parit adalah CPO yang terikat pada air limbah pabrik minyak sawit. CPO parit memiliki kadar free fatty acid (FFA) antara 40 sampai $70 \%$. Kadar FFA CPO yang tinggi tersebut dapat diturunkan melalui reaksi esterifikasi dengan bantuan katalis $\mathrm{SiO}_{2} / \mathrm{SO}_{3}{ }^{-} \mathrm{H}^{+}$. Pada penelitian ini, konsentrasi katalis $\mathrm{SiO}_{2} / \mathrm{SO}_{3} \mathrm{H}^{+}$divariasikan yaitu 1,3 , dan $5 \%$ (b/b). Dari hasil penelitian, kinerja katalis terbaik diperoleh pada konsentrasi 5\% dengan kemampuan menurunkan kadar FFA sebesar 49,70\%.

Kata kunci: silika tersulfatasi, sekam padi, sol-gel, CPO parit, esterifikasi 


\section{Pendahuluan}

Berdasarkan data United States Department of Agriculture (USDA) tahun 2010, Indonesia merupakan produsen minyak kelapa sawit terbesar di dunia dengan produksi sebesar $46 \%$. Hal ini menunjukkan adanya peluang yang besar bagi Indonesia untuk mengembangkan biodiesel dengan bahan baku minyak kelapa sawit atau crude palm oil (CPO). Namun, penggunaan $\mathrm{CPO}$ secara langsung sebagai bahan baku biodiesel akan menimbulkan masalah terkait dengan ketahanan pangan dan masalah lingkungan seperti kerusakan tanah, penggundulan hutan, dan penggunaan yang berlebihan dari tanah yang subur. Selain itu, dalam kurun waktu 10 tahun terakhir harga minyak nabati meningkat secara drastis yang akan mempengaruhi kelangsungan hidup industri biodiesel (Balat, 2010). Saat ini, terus berkembang penelitian untuk menghasilkan biodiesel dengan bahan baku minyak goreng bekas, tetapi infrastruktur pengumpulan dan logistiknya masih menjadi hambatan dari sumber bahan baku yang umumnya tersebar (Sharma dan Singh, 2009). Untuk itu pada penelitian ini akan digunakan bahan baku CPO parit yang merupakan limbah cair pabrik minyak sawit.

Crude palm oil (CPO) parit adalah CPO yang terikat pada air limbah pabrik minyak sawit. CPO parit memiliki kadar FFA antara 40 sampai 70\%. Komponen utama CPO parit terdiri dari $95-96 \%$ air, 0,6-0,7\% minyak dan 4-5\% berbagai macam padatan (Nugroho dkk., 1997). Dibalik keunggulannya, CPO parit memiliki kelemahan sebagai bahan baku biodiesel, yaitu memiliki kadar FFA tinggi yang menyebabkan proses pembuatan biodiesel akan terganggu dengan terbentuknya sabun dalam jumlah besar (Lotero dkk., 2005). Untuk mengatasi masalah tersebut, perlu dilakukan esterifikasi untuk menurunkan kadar FFA CPO parit melalui konversi asam lemak bebas menjadi metil ester. Reaksi esterifikasi akan dilakukan dengan bantuan katalis silika tersulfatasi yang disintesis dari sekam padi.

Sekam padi merupakan limbah pertanian yang diperoleh dari hasil samping butir padi. Berdasarkan data FAO (2008) jumlah sekam padi yang dihasilkan di Indonesia mencapai lebih dari 11,6 juta ton per tahun. Data ini menggambarkan bahwa jika dapat dimanfaatkan untuk produk bernilai ekonomis, residu pertanian tersebut akan mampu berperan sebagai penyumbang nilai tambah yang cukup signifikan bagi para petani. Menurut Della dkk. (2002), sekam padi yang sudah mengalami pembakaran menjadi abu mengandung silika dengan kadar yang tinggi, sekitar $87-97 \%$ dan sisanya berupa oksida logam. Data tersebut mencerminkan bahwa sekam padi sangat berpotensi untuk dimanfaatkan sebagai sumber silika. Dengan keunggulannya, maka dalam penelitian ini digunakan katalis heterogen $\mathrm{SiO}_{2} / \mathrm{SO}_{3} \mathrm{H}^{+}$yang disintesis dari abu sekam padi. Silika tersulfatasi $\left(\mathrm{SiO}_{2} / \mathrm{SO}_{3}{ }^{-} \mathrm{H}^{+}\right)$yang disintesis menggunakan metode sol-gel merupakan katalis dengan luas permukaan besar dan bersifat asam (Izumi dkk., 1999) sehingga diharapkan katalis ini memiliki kinerja yang baik dalam reaksi esterifikasi asam lemak bebas CPO parit.

\section{Metode Penelitian}

\subsection{Bahan Penelitian}

Bahan-bahan yang digunakan dalam penelitian ini terdiri dari sekam padi, CPO parit yang diambil dari salah satu pabrik CPO di Kecamatan Rangai Tri Tunggal Kabupaten Lampung Selatan Provinsi Lampung, kertas Whatman 42, dan aquades. Bahan kimia lain yang digunakan memiliki kualitas pro analysis dari Merck, diantaranya $\mathrm{HCl}, \mathrm{H}_{2} \mathrm{SO}_{4}$, Metanol, $\mathrm{KOH}, \mathrm{NaOH}$, dan indikator PP.

\subsection{Alat Penelitian}

Alat yang digunakan dalam penelitian ini terdiri dari hotplate stirrer, oven, tanur (furnace), ayakan 250 mesh, kondensor refluks, labu leher tiga, termometer, neraca analitik (Mettler-AT 200), buret, spektrofotometer IR (Shimadzu FTIR 8201 PC), dan peralatan gelas yang umum digunakan di laboratorium kimia.

\subsection{Cara Penelitian}

\subsubsection{Sintesis dan karakterisasi silika tersulfatasi \\ Sebelum dilakukan sintesis, sekam padi}


dipreparasi terlebih dahulu. Sebanyak 150 gram sekam padi dicuci dengan air kran sampai air bilasannya jernih sebagai tanda hilangnya pengotor. Selanjutnya, sekam padi dijemur sampai kering. Sintesis silika dari sekam padi dilakukan menggunakan metode sol-gel. Sebanyak 20 gram sekam padi yang sudah dipreparasi, direndam dalam $800 \mathrm{~mL}$ larutan $\mathrm{NaOH} 1$ M kemudian dipanaskan sampai mendidih sambil diaduk selama 1 jam. Larutan yang dihasilkan didinginkan selama 24 jam pada suhu ruang. Selanjutnya, larutan tersebut disaring menggunakan kertas saring dan diambil filtratnya. Filtrat yang diperoleh ditambahkan $\mathrm{HCl}$ 0,6 M sambil diaduk. Penambahan $\mathrm{HCl}$ divariasikan sampai $\mathrm{pH}$ larutan yang terbentuk adalah 7, 8, dan 9. Ketiga larutan tersebut didiamkan pada suhu ruang selama 24 jam sampai terbentuk hidrogel.

Hidrogel yang diperoleh ditambahkan 1,5 L aquades dan diaduk dengan pengaduk magnet selama 10 menit. Larutan yang diperoleh disaring menggunakan kertas saring. Gel hasil penyaringan dipanaskan di dalam oven pada suhu $100^{\circ} \mathrm{C}$ selama 2 jam sehingga dihasilkan padatan. Padatan yang diperoleh dihaluskan menggunakan lumpang dan mortar.

Untuk meningkatkan sifat keasamannya, silika yang dihasilkan diimpregnasi dengan larutan $\mathrm{H}_{2} \mathrm{SO}_{4}$. Sebanyak 1,5 gram silika dimasukkan ke dalam $300 \mathrm{~mL} \mathrm{\textrm {H } _ { 2 } \mathrm { SO } _ { 4 }}$ 0,5 M. Larutan tersebut diaduk menggunakan pengaduk magnet selama 8 jam dan disaring. Padatan hasil penyaringan dipanaskan pada suhu $400{ }^{\circ} \mathrm{C}$ selama 2 jam untuk menguapkan asam sulfat yang tidak terikat pada silika. Katalis yang dihasilkan dikarakterisasi dengan FT-IR.

\subsubsection{Esterifikasi CPO parit}

Sebanyak 3 L CPO parit dipanaskan pada suhu $130{ }^{\circ} \mathrm{C}$ untuk menguapkan air yang ada di dalam CPO parit kemudian CPO parit panas disaring dengan kertas saring untuk memisahkan pengotor padat yang berukuran besar. Selanjutnya, 150 gram CPO parit diesterifikasi dengan metanol, perbandingan mol minyak jelantah dan metanol adalah 1:12, dengan asumsi berat molekul CPO parit adalah 860, maka berat metanol yang digunakan adalah 67 gram. Konsentrasi katalis $\mathrm{SiO}_{2} / \mathrm{SO}_{3}{ }^{-} \mathrm{H}^{+}$yang digunakan divariasikan, yaitu 1,3 , dan $5 \%$ dari berat total $\mathrm{CPO}$ parit dan metanol. Katalis $\mathrm{SiO}_{2} / \mathrm{SO}_{3}{ }^{-} \mathrm{H}^{+}$dan metanol direfluks terlebih dahulu menggunakan labu leher tiga yang dilengkapi pengaduk magnet selama 30 menit. Kemudian CPO parit yang sebelumnya telah dipanaskan sampai suhu $45{ }^{\circ} \mathrm{C}$ dimasukkan sedikit demi sedikit ke dalam campuran tersebut. Suhu dinaikkan sampai $60{ }^{\circ} \mathrm{C}$ dengan kecepatan putar pengaduk magnet 600 rpm dan dipertahankan selama 2 jam. Minyak hasil refluks dipisahkan dari komponen lain dengan centrifuge dengan kecepatan putar 1500 rpm selama 20 menit.

\subsubsection{Penentuan kadar FFA minyak hasil esterifikasi}

Penentuan kadar FFA menggunakan metode titrasi asam-basa. Sebanyak 2 gram minyak hasil esterifikasi dicampurkan dengan $20 \mathrm{~mL}$ metanol $96 \%$ dan dipanaskan sampai suhu $45{ }^{\circ} \mathrm{C}$. $\mathrm{Ke}$ dalam campuran tersebut ditambahkan 3 tetes indikator PP. Campuran dititrasi dengan $\mathrm{NaOH}$ 0,1 $\mathrm{N}$ hingga terjadi perubahan warna menjadi merah muda yang bertahan selama 15 detik. Titrasi dilakukan 2 kali untuk masing-masing sampel. Kadar FFA ditentukan dengan persamaan berikut:

$\% F F A=\frac{m L N a O H \times N ~ N a O H}{\text { berat contoh } \times 1000} \times 100 \%$

\section{Hasil dan Pembahasan}

\subsection{Sintesis dan Karakterisasi}

Pada sintesis silika dari sekam padi menggunakan metode sol-gel, penambahan $\mathrm{HCl}$ divariasikan, yaitu pada $\mathrm{pH} 7,8$, dan 9. Hasilnya menunjukkan bahwa hidrogel paling banyak terbentuk pada $\mathrm{pH} 8$, pada $\mathrm{pH} 7$ belum terbentuk hidrogel sama sekali, dan pada $\mathrm{pH} 9$ hidrogel yang terbentuk sangat sedikit. Sehingga, dapat disimpulkan bahwa $\mathrm{pH}$ optimum yang menghasilkan silika paling banyak adalah 8 .

Gambar 1a, 1b dan 1c masing-masing menunjukkan silika gel hasil sintesis dari sekam padi,silika padatan yang berasal dari silika gel yang dipanaskan, dan silika tersulfatasi 


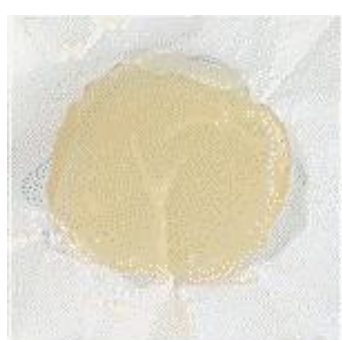

(a)

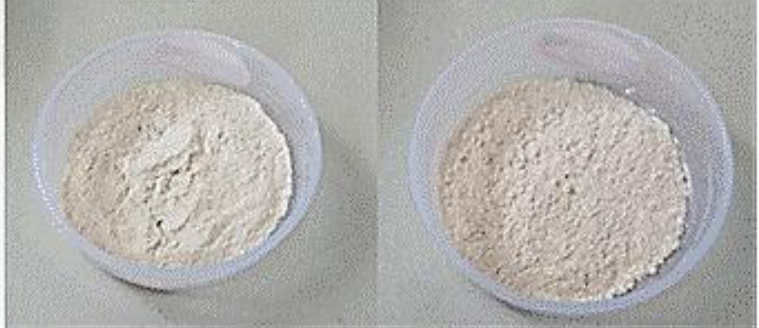

(b) (c)

Gambar 1. (a) Silika gel; (b) Silika; (c) Silika tersulfatasi

Tabel 1. Interpretasi spektra IR silika dan silika tersulfatasi terhadap referensi

\begin{tabular}{ccccl}
\hline & \multicolumn{3}{c}{ Bilangan gelombang $\left(\mathrm{cm}^{-1}\right)$} & \\
\cline { 2 - 4 } No & Silika & Silika tersulfatasi & Manríquez, $(2004)$ & \multicolumn{1}{c}{ Jenis vibrasi } \\
\hline 1 & 3453,88 & 3459,67 & $3300-3500$ & Rentang -OH (Si-OH) \\
2 & 1655,59 & 1630,52 & 1635 & Bengkokan -OH (Si-OH) \\
3 & 1187,94 & 1023,05 & 1100 & Rentang asimetri Si-O- (Si-O-Si) \\
4 & 773,31 & 776,20 & 800 & Rentang simetri Si-O- (Si-O-Si) \\
5 & 405,94 & 408,83 & 460 & Bengkokan Si-O (Si-O-Si) \\
\hline
\end{tabular}

$\left(\mathrm{SiO}_{2} / \mathrm{SO}_{3}{ }^{-} \mathrm{H}^{+}\right)$. Silika dan silika tersulfatasi secara fisik tidak memiliki banyak perbedaan. Keduanya merupakan padatan berwarna putih, tetapi pada silika tersulfatasi, butirannya lebih halus. Hal ini dimungkinkan karena kristalinitas dari $\mathrm{SiO}_{2}$ yang menurun akibat penambahan asam sulfat.

Spektra IR $\mathrm{SiO}_{2}$ dan $\mathrm{SiO}_{2} / \mathrm{SO}_{3}{ }^{-} \mathrm{H}^{+}$ditunjukkan pada Gambar 2. Gambar tersebut menunjukkan pita yang serupa dari $\mathrm{SiO}_{2}$ dan $\mathrm{SiO}_{2} / \mathrm{SO}_{3}{ }^{-} \mathrm{H}^{+}$. Menurut Salman (2015) pembentukan silika gel terjadi melalui 3 tahapan reaksi. Tahap pertama adalah pembentukan natrium silikat $\left(\mathrm{Na}_{2} \mathrm{SiO}_{3}\right)$ melalui reaksi antara $\mathrm{NaOH}$ dengan silika sekam padi yang ditunjukkan pada reaksi (1). Tahap kedua adalah pembentukan gugus silanol dari reaksi antara natrium silikat dengan suatu asam kuat yang dalam penelitian ini menggunakan $\mathrm{HCl}$. Gugus siloksi ( $\left.\mathrm{Si}^{-} \mathrm{O}^{-}\right)$dalam natrium silikat bereaksi dengan ion $\mathrm{H}^{+}$dari $\mathrm{HCl}$ membentuk silanol (Si-OH) sesuai persamaan reaksi (2). Tahap ketiga adalah reaksi antara silanol dengan atom $\mathrm{O}$ dari gugus siloksi yang lain membentuk siloksan (Si-O-Si) yang ditunjukkan oleh reaksi (3). Puncak-puncak yang muncul dalam spektra IR silika dan silika tersulfatasi telah mengonfirmasikan ketiga reaksi tersebut.

$$
\begin{aligned}
& \mathrm{SiO}(s)+2 \mathrm{NaOH}(a q) \rightarrow \mathrm{Na}_{2} \mathrm{SiO}_{3}(a q)+\mathrm{H}_{2} \mathrm{O}(l) \\
& \equiv \mathrm{Si}^{-} \mathrm{O}^{-}+\mathrm{H}^{+} \rightarrow \equiv \mathrm{Si}-\mathrm{OH} \\
& \equiv \mathrm{Si}-\mathrm{OH}+\equiv \mathrm{Si}-\mathrm{O}^{-} \rightarrow \equiv \mathrm{Si}-\mathrm{O}-\mathrm{Si} \equiv+\mathrm{OH}^{-}
\end{aligned}
$$

Hasil interpretasi spektra IR silika dan silika tersulfatasi ditunjukkan pada Tabel 1. Pita yang melebar antara 3300 dan $3500 \mathrm{~cm}^{-1}$ menunjukkan regangan $\mathrm{O}-\mathrm{H}$ yang terikat pada air $(\mathrm{Si}-\mathrm{OH})$. Pita ini terkonfirmasi melalui puncak pada panjang gelombang sekitar $1635 \mathrm{~cm}^{-1}$ yang merupakan vibrasi bengkokan molekul air. Vibrasi asimetrik dari atom silika yang ada pada siloksan (Si-O-Si) muncul yang muncul pada puncak sekitar $1100 \mathrm{~cm}^{-1}$ dan puncak ini tumpang tindih dengan vibrasi regangan $\mathrm{S}-\mathrm{OH}$ dari ion sulfat. Menurut Manríquez (2004) spektra IR yang dihasilkan menunjukkan bahwa gugus sulfat terikat pada atom silika sebagai gugus terkoordinasi mono.

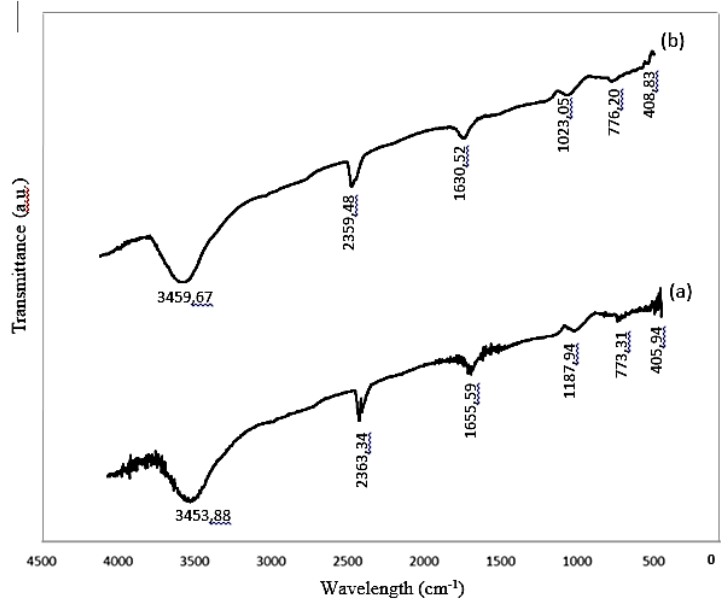

Gambar 2. Spektra (a) Silika and (b) Silika Tersulfatasi. Gambar FTIR tanpa background subtraction. 


\subsection{Reaksi Esterifikasi}

Gambar 3 menunjukkan hasil esterifikasi CPO parit dengan katalis silika tersulfatasi menggunakan reaktor batch. Esterifikasi pada CPO parit bertujuan untuk mengurangi kadar FFA yang terkandung dalam CPO parit melalui konversi asam lemak bebas menjadi metil ester. Esterifikasi umum dilakukan dalam pembuatan biodiesel dengan bahan baku yang memiliki kadar FFA tinggi, seperti CPO parit. Minyak yang dihasilkan belum bisa digunakan sebagai bahan bakar, perlu dilakukan reaksi lanjut, yaitu reaksi transesterifikasi untuk mengonversi trigliserida dalam CPO parit menjadi metil ester.

Dalam penelitian ini konsentrasi katalis silika tersulfatasi yang digunakan divariasikan yaitu 1, 3 dan 5\% untuk mengetahui konsentrasi optimum silika tersulfatasi dalam menurunkan kadar FFA CPO parit. Penurunan kadar FFA ditentukan melalui metode titrasi.

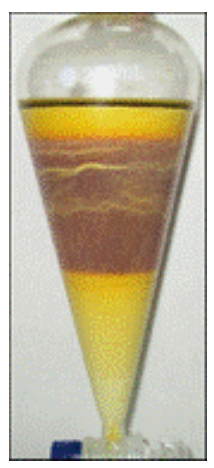

Gambar 3. Hasil esterifikasi CPO parit

\subsection{Penentuan kadar FFA CPO parit}

Gambar 4 menunjukkan grafik hubungan antara konsentrasi katalis dengan kadar FFA CPO parit. Berdasarkan Gambar 4 diketahui bahwa dengan meningkatnya konsentrasi katalis maka daya penurunan FFA CPO parit juga semakin meningkat. Konsentrasi katalis paling optimum dalam menurunkan kadar FFA CPO parit adalah 5\%. Hasilnya menunjukkan kadar FFA CPO Parit turun dari 8,37\% menjadi 4,21\%. Artinya, penurunan kadar FFA mencapai $49,70 \%$.

Menurut Brown (2000) reaksi esterifikasi terjadi melalui serangan proton yang berasal dari situs asam pada katalis ke arah gugus karbonil dari asam lemak bebas. Semakin banyak situs asam yang terlibat, maka semakin besar kemungkinan terjadinya serangan. Dengan meningkatnya konsentrasi katalis, maka semakin meningkat pula jumlah situs asam yang terlibat dalam reaksi, sehingga pada penelitian ini konsentrasi paling optimum adalah konsentrasi tertinggi, yaitu $5 \%$.

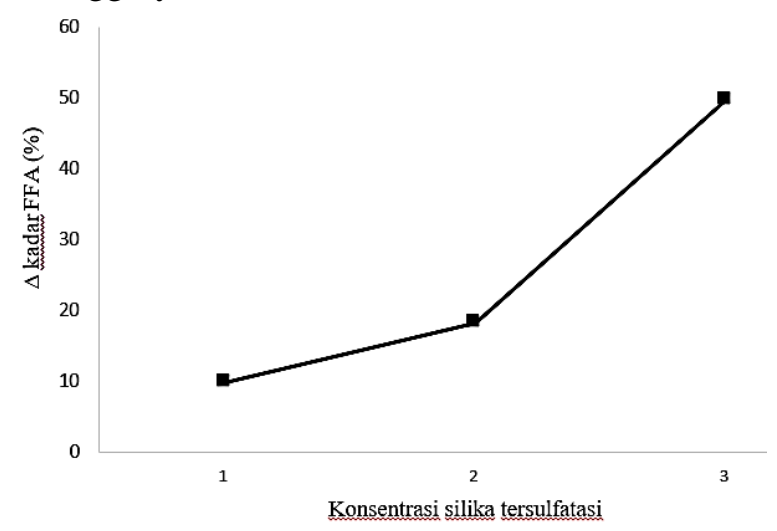

Gambar 4. Grafik hubungan antara konsentrasi silika tersulfatasi dengan $\Delta$ kadar FFA CPO parit

\section{Kesimpulan}

Secara fisik padatan silika tersulfatasi $\left(\mathrm{SiO}_{2} / \mathrm{SO}_{3}{ }^{-} \mathrm{H}^{+}\right)$berwarna putih. Hasil analisis dengan spektrofotometer IR menunjukkan bahwa gugus sulfat terikat pada silika sebagai gugus terkoordinasi mono. Sebagai katalis asam padat, silika tersulfatasi mampu menurunkan kadar asam lemak bebas CPO parit melalui konversi asam lemak bebas menjadi metil ester. Performa terbaik silika tersulfatasi diperoleh pada konsentrasi 5\% (b/b) terhadap CPO parit dan metanol. Perlu dilakukan penelitian lebih lanjut mengenai morfologi permukaan pori silika tersulfatasi, serta pengaruh suhu terhadap kristalinitas silika tersulfatasi.

\section{Ucapan Terima Kasih}

Penulis mengucapkan terima kasih kepada Institut Teknologi Sumatera atas bantuan dana penelitian yang diberikan melalui Hibah Mandiri ITERA.

\section{Daftar Pustaka}

Balat, M. and Balat, H., 2010, Progress in biodiesel processing, Appl. Energy, 87(6), 1815-35. 
Brown, W.H., 2000, Introduction to Organic Chemistry, $2^{\text {nd }}$ ed, Saunders College Publishing, Orlando.

Della, V.P., Kuhn, I., and Hotza, D., 2002, Rice Husk Ash as an Alternate Source for Active Silica Production, Mater. Lett., 57, 818-821.

Food and Agriculture Organization (FAO), 2008, FAO Rice Market Monitor 11 (2), United Nations, Rome.

Izumi, Y., K., Hisano, K. and Hida, T., 1999, Acid catalysis of silica-included heteropolyacid in polar reaction media, Applied Catalysis A: General, Vol.181, No. 2, pp. 277-282.

Lotero, E., Liu, Y., Lopez, D.E., Suwannakarn, K., Bruce, D.A. and Goodwin, J.G., 2005, Synthesis of biodiesel via acid catalysis, Ind. \& Eng. Chem. Res., 44(14), 5353-5363.
Manríquez, M.E., López T., Gomez R., Picquart M., and Hernández-Cortez J.G., 2004, Sol-gel silica modified with phosphate and sulfate ions, Journal of Non-Crystalline Solids, Vol. 345-346 pp.643-646.

Sharma, Y.C. and Singh, B., 2009, Development of biodiesel: Current scenario, Renew. Sustain. Energy Rev., 13(6-7), 1646-1651.

Salman, M.N., Krisdiyanto, D., Khamidinal dan Arsanti, P., 2015, Preparasi katalis silka sulfat dari abu sekam padi dan uji katalitik pada reaksi esterifikasi gliserol dengan anhidrida asam asetat, Reaktor, 15, 231-240.

USDA, 2010, Foreign Agricultural Service: production, supply and distribution, Available at: http://www.fas.usda.gov/psdonline/ psdQuery.aspx. 